\title{
RELAÇÕES TECTÔNICAS DO MAGMATISMO ALCALINO DO PARAGUAI ORIENTAL
}

\author{
Victor Fernandez VELÁZQUEZ \\ Claudio RICCOMINI \\ Celso de Barros GOMES \\ Lucia de FIGUEREDO \\ Carlos FIGUEREDO
}

\begin{abstract}
RESUMO
O magmatismo alcalino no Paraguai está distribuído em seis províncias (Alto Paraguai, Rio Apa, Amambay, Central, Misiones e Assunção), com idades variando entre o PermoTriássico e o Eoceno. Estas províncias, em quase sua totalidade localizadas no Paraguai Oriental, estão freqüentemente associadas com feições estruturais maiores, principalmente falhas, com expressão magnética e/ou gravimétrica. Este artigo objetiva integrar os dados geológicos e geofísicos disponíveis de modo a se estabelecer, numa primeira aproximação, os controles tectônicos do magmatismo alcalino do Paraguai.
\end{abstract}

\section{ABSTRACT}

The alkaline magmatism of Paraguay is distributed in six provinces (Alto Paraguay, Rio Apa, Amambay, Central, Misiones and Assunção), with ages varying between PermianTriassic and Eocene. These provinces, located in Eastern Paraguay, are frequently associated with major structural features, mainly faults, with magnetic and/or gravimetric expression. In this paper geologic and geophysical data are integrated in order to establish, as a first approximation, the tectonic controls for this alkaline magmatism.

\section{INTRODUÇÃO}

O Paraguai reúne inúmeras ocorrências de rochas alcalinas de idade permo-triássica a paleógena. Elas estão concentradas em seis províncias: Alto Paraguai, Rio Apa, Amambay, Central, Misiones e Assunção (VELÁZQUEZ et al., 1996). Uma revisão das características geológicas principais, aliada à análise de mapas gravimétrico e aeromagnetométrico, permite delinear, ainda que em linhas gerais, o controle tectônico do magmatismo alcalino do Paraguai. Uma primeira aproximação sobre o tema é apresentada neste trabalho.

\section{AS GRANDES UNIDADES GEOLÓGICAS DO PARAGUAI ORIENTAL}

No Paraguai Oriental, são conhecidas duas exposições maiores de rochas pré-cambrianas
(FIGURA 1). A primeira, na porção norte do Paraguai Oriental, corresponde à terminação sul do Cráton Amazônico, sendo composta por rochas gnáissicas, graníticas, metassedimentares e metavulcânicas (PROYECTO PAR 83/005, 1986; WIENS, 1986), de provável idade arqueana a paleoproterozóica; sobre estas rochas foi depositada uma cobertura de margem cratônica eocambriana, além de sedimentos arenosos carboníferos. A segunda exposição, na porção sul do Paraguai Oriental, consiste numa associação de rochas metamórficas (gnaisses, anfibolitos, quartzitos) e granitóides, além de rochas vulcanossedimentares, de idade neoproterozóica (BITSCHENE \& LIPPOLT, 1986; KANZLER, 1987).

No Paleozóico ocorreu marcante subsidência, com extensa deposição de sedimentos rela- 
cionados a três seqüências: ordoviciana-siluriana, reunindo conglomerados, arenitos, siltitos e folhelhos; permo-carbonífera, com influência glacial (tilitos e diamictitos); e permiana, com sedimentos de caráter transgressivo (arenitos, siltitos e argilitos) (HARRINGTON, 1972; ORUÉ, 1996).

O Mesozóico foi palco de importante atividade magmática extrusiva relacionada com a abertura do Oceano Atlântico Sul. A parte leste do Paraguai Oriental esteve sujeita a um ambiente desértico (HARRINGTON, 1950; PUTZER, 1962), com extensa sedimentação eólica, em parte interdigitada com os derrames vulcânicos toleíticos de idade eocretácea (RENNE et al., 1992; TURNER et al., 1994). Nesta região, arenitos neocretáceos recobrem os derrames (PROYECTO PAR 83/005, 1986).

$\mathrm{Na}$ região de Assunção, ocorre espesso pacote rudáceo (Formação Patiño), com deposição associada à movimentação de falhas normais. Sedimentos quaternários encontram-se distribuídos ao longo do leito dos principais rios, assim como também em áreas de planícies alagadiças, incluindo depósitos arenosos muito heterogêneos e materiais argilosos (ORUÉ, 1996).

Merecem destaque as seis províncias alcalinas (Alto Paraguai, Rio Apa, Amambay, Central, Misiones e Assunção), com idades entre o Permo-Triássico e o Eoceno (VELÁZQUEZ et al., 1996; FIGURA 1).

\section{ANÁLISE DOS DADOS GEOFÍSICOS}

A megaestruturação do Paraguai Oriental pode ser melhor compreendida graças ao aporte de dados geofísicos obtidos durante o programa de levantamentos geológicos básicos, coordenado pela empresa The Anschutz Corporation, desenvolvido na década de oitenta e princípios da década de noventa, quando foram elaborados mapas aeromagnetométrico e gravimétrico.

O mapa aeromagnetométrico foi elaborado pela empresa AERIAL GEOPHYSICS COMPANY (1980) a partir de linhas de vôo de baixa altitude, com duas direções principais, N-S e EW. Os dados gravimétricos foram obtidos pela empresa PHOTO GRAVITY CORPORATION (1991) empregando o gravímetro modelo GRS67, para a medição da aceleração da gravidade, tendo sido levantadas 3.679 estações, distribuídas ao longo das principais estradas, estas por sua vez interligadas à rede gravimétrica internacional IGNS. Os registros permitiram elaborar um mapa residual de anomalia Bouguer, com um intervalo de $5 \mathrm{mGal}$ entre os contornos, sob padrão de densidade de redução de $2.670 \mathrm{~kg} / \mathrm{m}^{3}$.

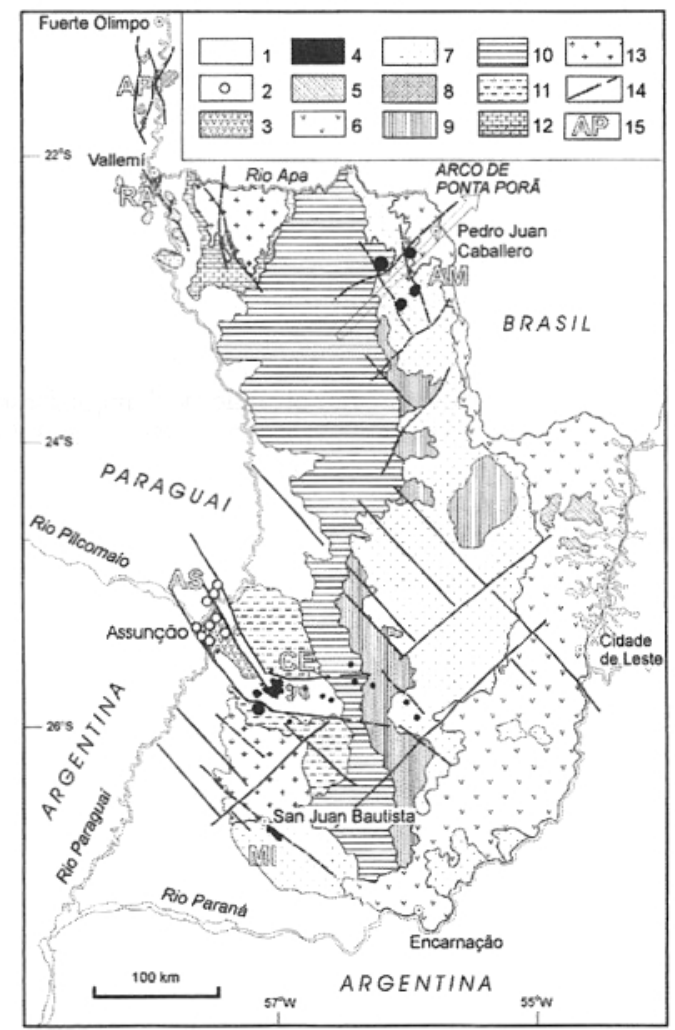

FIGURA 1 - Mapa geológico do Paraguai Oriental (distribuição das unidades baseada em THE ANSCHUTZ CORPORATION, 1987): 1. Coberturas sedimentares quaternárias; 2 . Rochas alcalinas cenozóicas; 3. Depósitos cenozóicos da Formação Patiño; 4. Rochas alcalinas cretáceas; 5 . Depósitos sedimentares neocretáceos da Formação Acaray; 6. Derrames toleíticos eocretáceos da Formação Alto Paraná; 7. Arenitos eocretáceos da Formação Misiones; 8. Rochas alcalinas permo-triássicas; 9. Unidades sedimentares permianas do Grupo Independência; 10 Unidades sedimentares permo-carboníferas do Grupo Coronel Oviedo; 11. Unidades sedimentares ordovicianas-silurianas dos grupos Caacupé e Itacurubi; 12. Rochas carbonáticas neoproterozóicas do Grupo Itapucumi; 13. Embasamento arqueano a neoproterozóico; 14. Falhas principais, tracejadas quando inferidas; 15. Províncias alcalinas (AP - Alto Paraguai; RA - Rio Apa; AM - Amambay; CE - Central; MI Misiones; AS - Assunção).

Por questões de escala, para o presente trabalho foi gerado um mapa em escalas de cinza, por reamostragem e krigagem ordinária de 500 pontos dos cerca de 38.000 disponíveis no mapa 
aeromagnetométrico original digitalizado (FIGURA 2). O mapa residual de anomalia Bouguer foi também simplificado, adotando-se um intervalo de $10 \mathrm{mGal}$ entre os contornos (FIGURA 3). No mapa aeromagnetométrico (FIGURA 2) as principais anomalias positivas correspondem a alinhamentos estruturais retilíneos, com direção predominante NW-SE, secundariamente NE-SW, separando blocos marcados por isolinhas de valores intermediários e comportamento não linear. Nota-se, por vezes, o deslocamento anti-horário dos alinhamentos de direção NW-SE pelos alinhamentos orientados segundo NE-SW. Esses deslocamentos são mais evidentes ao sul do paralelo $24^{\circ} 00^{\prime}$ 'S. No geral, a disposição desses alinhamentos é semelhante àquela verificada na borda leste da Bacia do Paraná, no Brasil (v.g. FERREIRA et al., 1982).
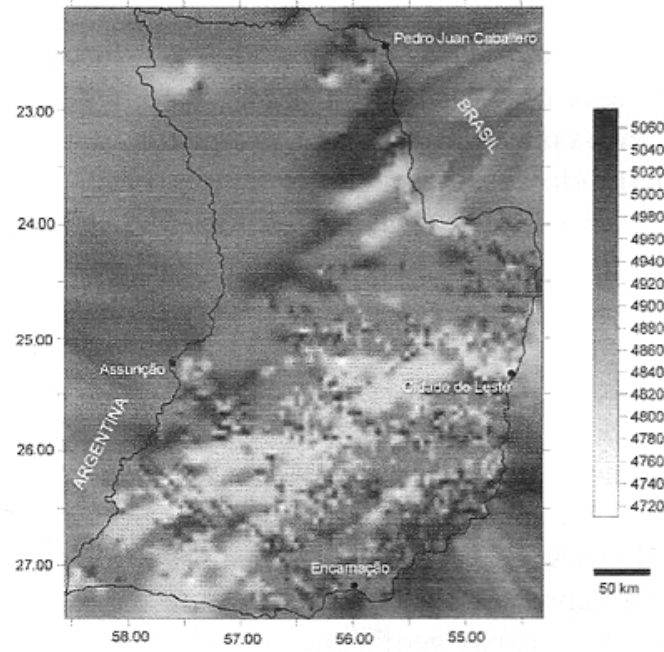

FIGURA 2 - Mapa em escalas de cinza obtido a partir do mapa aeromagnético do Paraguai Oriental, elaborado pela AERIAL GEOPHYSICS COMPANY (1980). Escala em gamma.

No mapa da FIGURA 3 verifica-se que, em geral, as feições gravimétricas guardam boa concordância com aquelas encontradas no mapa regional de anomalia Bouguer da América do Sul (BREVILLE et al., 1973; QUINTAS, 1994), como também no mapa elaborado por VIDOTTI et al. (1998) para a Bacia do Paraná. Numa primeira análise do mapa, pode-se verificar a existência de dois tipos de anomalias de gradiente gravimétrico bem distintas. O primeiro tipo de anomalia é nitidamente circular, caracterizado por isolinhas de gradiente baixo, situadas nas proximidades das cidades de Pedro Juan Caballero, Assunção e Encarnação. O segundo tipo possui formato mais linear, descrevendo uma longa faixa entre os meridianos $56^{\circ} 00^{\prime}$ e $58^{\circ} 00^{\prime} \mathrm{W}$, com direção N-S até o paralelo $26^{\circ} 00^{\prime} \mathrm{S}$ e, a partir deste ponto, com uma leve deflexão para SE, mostrando assinatura gravimétrica de primeira ordem, com anomalia chegando até $-25 \mathrm{mGal}$.

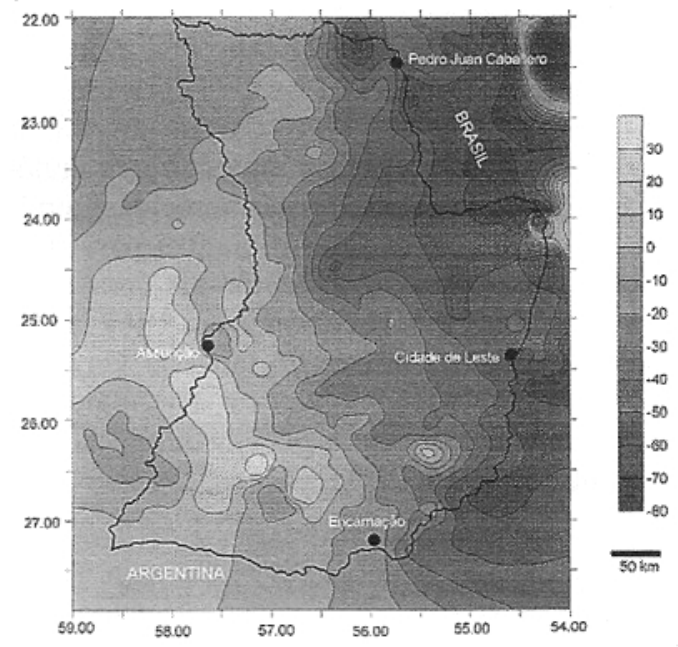

FIGURA 3 - Mapa residual de anomalia Bouguer do Paraguai Oriental, elaborado, com simplicação, a partir do mapa da PHOTO GRAVITY CORPORATION (1991). Escala em mGal.

As variações observadas nas amplitudes das anomalias magnéticas e Bouguer foram consideradas como decorrentes de feições estruturais, uma vez que as curvas de isovalores exibem importante comportamento linear e, em diversos casos, guardam inteira concordância com estruturas (falhas e fraturas) previamente identificadas no campo e em trabalhos anteriores (v.g. PUTZER, 1962; THE ANCHUTZ CORPORATION, 1987; FÚlFARO, 1996). As feições estruturais assim interpretadas foram incorporadas no mapa geológico da FIGURA 1.

\section{RELAÇÕES TECTÔNICAS DO MAGMATISMO ALCALINO}

A atividade magmática alcalina no Paraguai Oriental pode ser agrupada em três eventos tectono-magmáticos principais: Permo-Triássico, Eocretáceo e Terciário (Eoceno).

\subsection{Permo-Triássico}

O evento magmático mais antigo, de idade permo-triássica (240-250 Ma), situa-se ao sul da 
localidade de Fuerte Olimpo, na zona fronteiriça entre o Paraguai e o Estado de Mato Grosso do Sul (Brasil). Reúne nefelina sienitos e sienitos, com gradações até granitos alcalinos, na forma de complexos anelares e stocks, ao lado dos correspondentes equivalentes finos, como lavas e diques, caracterizando a chamada Província Alto Paraguai. Este magmatismo, segundo LIVIERES \& QUADE (1987), estaria relacionado com o Arco do Rio Apa, estrutura de idade proterozóica. Entretanto, VELÁZQUEZ et al. (1996) consideraram essa atividade alcalina ligada a uma margem cratônica. Apesar das atenções já merecidas, ainda não se dispõe de dados suficientes para uma melhor caracterização. Levando em consideração a sua forma de ocorrência restrita, como corpos alinhados em estreita faixa ao longo do Rio Paraguai e a presença de alinhamentos estruturais, aventa-se a possibilidade de um controle por falhas de direção geral N-S.

\subsection{Eocretáceo}

O evento do Eocretáceo apresenta três pulsos magmáticos principais e compreende essencialmente rochas potássicas.

O primeiro pulso, entre 135-140 Ma, precede os basaltos toleíticos da Formação Alto Paraná (Formação Serra Geral, no Brasil). Está bem representado nas localidades de Vallemí (Província Rio Apa) e Pedro Juan Caballero (Província Amambay), ao norte e nordeste do Paraguai Oriental, respectivamente. O magmatismo da Província Rio Apa é pouco expressivo, aparecendo como pequenos diques de filiação lamprofírica e carbonatítica, alojados em falhas de pequeno rejeito de direção geral NE$\mathrm{SW}$, mas com magnitudes suficientes para permitir a migração de líquidos primitivos de natureza mantélica até a superfície da crosta, seccionando todo o pacote de rochas carbonáticas de idade eocambriana. Na Província Amambay, a atividade alcalina é representada por complexos anelares, como Cerro Chiriguelo e Cerro Sarambí, tendo fácies carbonatítica como o principal tipo litológico dessas intrusões. Ocorrem também piroxenitos, shonkinitos, fenitos e diques de traquitos e fonolitos, presentes em Cerro Guazú, Cerro Apuá e Cerro Tayay. Tectonicamente, a região encontra-se no domínio do Arco de Ponta Porã (THOMAS \& ASSOCIATES, 1976). Este arco, com direção NE-SW, interpõe-se entre duas importantes depressões evidenciadas pelas anomalias
Bouguer, situadas a NW e SE de Pedro Juan Caballero. É provável que tais depressões representem bacias sedimentares, tendo o Arco de Ponta Porã o comportamento de um bloco tectonicamente soerguido, controlando as intrusões alcalinas de Cerro Chiriguelo e Cerro Sarambí. A presença de anomalias magnéticas de intensidade mais elevada no extremosudoeste do arco soma a favor desta hipótese. Um controle tectônico das intrusões pelo Arco de Ponta Porã já havia sido anteriormente proposto por LIVIERES \& QUADE (1987).

O segundo pulso é representado pelo magmatismo da Província Central (FIGURA 4), com idade entre 118-132 Ma, em parte coetâneo ao magmatismo da Formação Alto Paraná. As ocorrências estão concentradas na porção centro-ocidental do Paraguai Oriental, reunindo um conjunto de rochas com grande diversidade petrográfica, de moderada a fortemente potássicas. São agrupadas em duas séries distintas, a primeira com basanitos a fonolitos e a segunda com basaltos alcalinos a traquitos, ambas incluindo seus respectivos termos intrusivos (COMIN-CHIARAMONTI \& GOMES, 1996). Adicionalmente, uma pequena ocorrência de lava de natureza carbonatítica foi também reconhecida nas imediações de Sapucai. No conjunto, as rochas desta província ocorrem como stocks, plugs, lavas, diques, incluindo também a grande intrusão de Cerro Acahay, e têm como principal controle estrutural o Rift de Assunção (DEGRAFF, 1985), instalado no Eocretáceo. Esta depressão tectônica, com forte expressão nos dois mapas geofísicos, apresenta uma largura variando entre 25 e $45 \mathrm{~km}$ e é constituída por três segmentos bem definidos (FIGURA 4): segmento ocidental, de orientação NW-SE, com cerca de $90 \mathrm{~km}$ de comprimento, desenvolvido para sudeste a partir dos arredores de Assunção, entre Benjamin Aceval e Paraguarí, com expressivas anomalias gravimétricas e magnetométricas; segmento central, orientado segundo E-W, de Paraguarí a Villarrica, com aproximadamente $75 \mathrm{~km}$; segmento oriental, instalado a partir de Villarrica para sudeste, num trecho menos definido, novamente de orientação NW-SE, até a região da Cordilheira de Ybytyruzú, com extensão de $40 \mathrm{~km}$. Em trabalho recente, a partir do estudo de diques, falhas e juntas, VELÁZQUEZ et al. (1998) sugerem que o rift foi gerado sob regime tectônico transcorrente dextral, com binário orientado segundo E-W. 


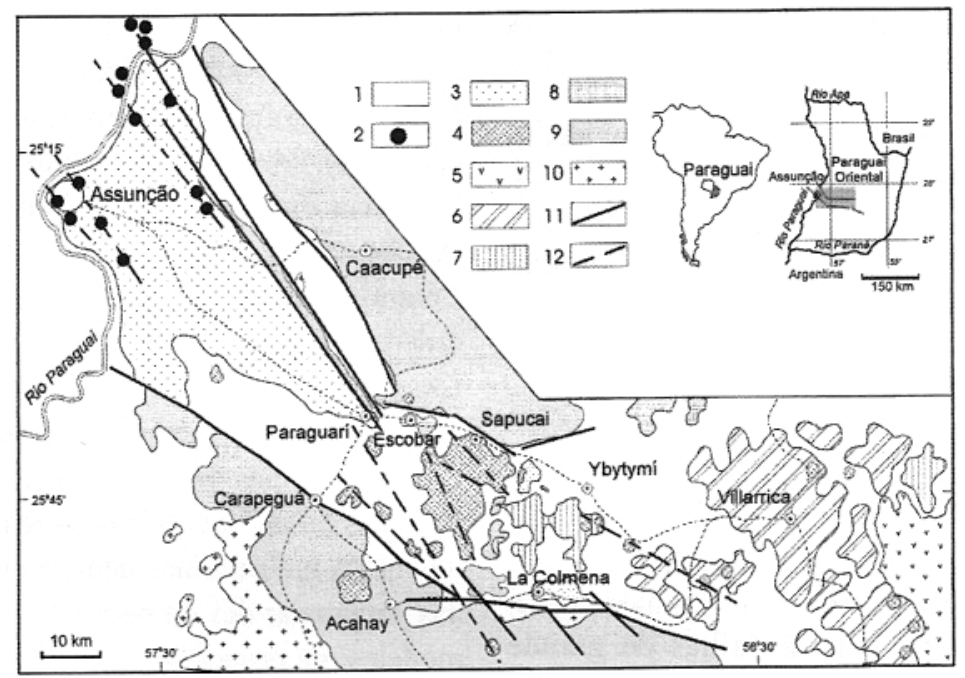

FIGURA 4 - Mapa geológico do Rift de Assunção (segundo VELAZQUEZ et al., 1998): 1. Coberturas sedimentares quaternárias; 2 . Rochas alcalinas cenozóicas (Província Assunção); 3. Depósitos cenozóicos da Formação Patiño; 4. Rochas alcalinas cretáceas (Província Central); 5. Derrames toleíticos eocretáceos da Formação Alto Paraná; 6 . Arenitos eocretáceos da Formação Misiones; 7. Unidades sedimentares permianas do Grupo Independência; 8. Arenitos, diamictitos e folhelhos permocarboníferos da Formação Aquidabán;9. Unidades sedimentares ordovicianas-silurianas dos grupos Caacupé e Itacurubi; 10. Embasamento neoproterozóico; 11. Falhas principais; 12. Alinhamentos de rochas alcalinas.

Um terceiro pulso magmático, ainda preliminarmente datado de cerca de $120 \mathrm{Ma}$, está registrado na parte sul do Paraguai Oriental, nos arredores da localidade de San Juan Bautista, enfeixado na denominada Província Misiones (VELÁZQUEZ et al., 1996). Inclui rochas alcalinas de composição sódica, como nefelinitos e fonolitos peralcalinos, que ocorrem sob a forma de pequenos plugs e diques (COMIN-CHIARAMONTI et al., 1992). Nessa região, conforme apontam os dados magnetométricos e gravimétricos, existe uma feição estrutural de grande porte, aproximadamente a $100 \mathrm{~km}$ ao sul do Rift de Assunção, formando uma faixa de direção NW-SE, com uma extensão superior a 150km. DEGRAFF \& ORUÉ (1984) atribuíram a designação de Gráben de Santa Rosa para essa feição, considerando-a resultante de fraturamento crustal. As observações de campo mostram que os corpos alcalinos desta província encontram-se distribuídos e orientados ao longo de tal estrutura.

\subsection{Terciário}

$\mathrm{O}$ último evento marca importante atividade tecnomagmática durante o Terciário, com idades entre 39 e $61 \mathrm{Ma}$, mas com forte predomínio no intervalo de 50-45 Ma (Eoceno). Está restrito à região centro-oeste do Paraguai Oriental, no segmento ocidental do Rift de Assunção (FIGURA
4), e reúne rochas de composição marcadamente sódica, principalmente nefelinitos e ankaratritos, portadoras de nódulos mantélicos que gradam desde dunitos a lherzolitos. As ocorrências estão relacionadas a um alinhamento magnético de direção NW-SE e a um baixo gravimétrico situado sobre a Cidade de Assunção. Estudos sistemáticos das falhas e fraturas presentes nos focos magmáticos concentrados no segmento ocidental do Rift de Assunção foram conduzidos por RICCOMINI et al. (1998). Nesse trabalho, os autores postulam que os corpos alcalinos foram colocados em zonas de falhas profundas $(>60 \mathrm{~km}$ de profundidade), de direção NW-SE, controlados por regime tectônico relacionado a um binário transcorrente dextral E-W, similar ao vigente durante a implantação do rift, no Eocretáceo.

\section{CONSIDERAÇÕES FINAIS}

A distribuição das ocorrências de rochas alcalinas no Paraguai Oriental mostra freqüente associação com feições estruturais maiores, principalmente falhas, que configuram anomalias magnéticas e/ou gravimétricas expressivas. Esta associação representa um critério básico na busca de ocorrências ainda não conhecidas.

A integração dos dados geofísicos e geológicos permitiu configurar, em linhas gerais, o controle tectônico do magmatismo alcalino do 
Paraguai Oriental, vinculado basicamente a três direções estruturais principais: N-S, NW-SE e NE-SW.

Apenas na região norte do país foram identificados alinhamentos estruturais de direção N-S, que parecem ter exercido controle nas intrusões da Província Alto Paraguai. Embora as informações geológicas dessa região sejam ainda insuficientes, esses alinhamentos poderiam refletir antigas estruturas do embasamento reativadas durante o magmatismo permo-triássico.

Os alinhamentos estruturais de direção NW-SE são os mais freqüentes e melhor definidos nas anomalias aeromagnéticas e gravimétricas. Em geral, esses alinhamentos representam falhas ou zonas de falhas de grande magnitude que permitiram a ascensão de volume considerável de magma alcalino gerado no manto sublitosférico. As evidências geológicas que conduzem a tais afirmativas são amplamente registradas na literatura. Nesse contexto tem-se o Rift de Assunção e o Gráben de Santa Rosa, ambas estruturas de idade cretácea, que controlaram as intrusões alcalinas das províncias Central, Assunção e Misiones.

Os alinhamentos de direção NE-SW são menos freqüentes, sendo o Arco de Ponta Porã, de idade eocretácea, a estrutura de maior importância, exercendo controle sobre as principais intrusões alcalinas da Província Amambay. Subordinadamente, podem ser mencionadas as pequenas falhas de orientação NE-SW, onde estão alojados diques alcalinos eocretáceos da Província Rio Apa. Estudos estruturais de maior detalhe, como aqueles realizados nas províncias Central e Assunção, aliados às informações de ordem petrológica e geofísica, levaram à caracterização do controle tectônico do magmatismo e dos regimes de esforços associados, além de permitir inferências mais seguras sobre a profundidade das falhas envolvidas. A realização de estudos dessa natureza nas demais províncias alcalinas paraguaias deverá permitir o refinamento dos modelos ora propostos.

\section{AGRADECIMENTOS}

Os autores externam seus agradecimentos aos dois revisores da Revista do IG pelas oportunas críticas e sugestões apresentadas; aos colegas William Sallum Filho e Alethéa Ernandes Martins pelo auxílio na preparação dos mapas geofísicos; ao Prof. Dr. Thomas R. Fairchild pela revisão do abstract e à FAPESP (Proc. 97/01210-4) pelo apoio financeiro.

\section{REFERÊNCIAS BIBLIOGRÁFICAS}

AERIAL GEOPHYSICS COMPANY. 1980. Composite Map of Aeromagnetic Survey Eastern Paraguay (Scale 1: 1.000.000). Asunción, Archivo DRM-MOPC.

BITSCHENE, P.R. \& LIPPOLT, H.J. 1986. Acid magmatites of the Brasiliano Cycle in East Paraguay. Zbl. Geol. Paläont., (9/10): 1457-1468.

BREVILLE, G.L.; BEIERLE, C.W.; SANDERS, J. R.; VOSS, J.T.; WILCOX, E.L. 1973. A Bouguer anomaly map of South America (Scale 1:10.000.000). St. Louis, Missouri. DMAAC (Defense Mapping Agency) Tech. Paper 73.2.

COMIN-CHIARAMONTI, P. \& GOMES, C.B. 1996. Alkaline magmatism in Eastern Paraguay. Relationships with coeval magmatism in Brazil. São Paulo, EDUSP/FAPESP, 458p.

; PETRINI, R.; DE MIN, A.; VELÁZQUEZ V.F.; ORUÉ, D. 1992. A new area of alkaline rocks in Eastern Paraguay. Rev. Bras. Geoc., 22:500-506.

DEGRAFF, J.M. 1985. Late Mesozoic crustal extension and rifting on the western edge of the Paraná Basin, Paraguay. Geol. Soc. Amer. Abst., 17:560.

\& ORUÉ, D. 1984. Proyecto tectónico del Paraguay Suroriental: informe de progreso al termino del trabajo de campo (2da. etapa). Asunción, MDNDIM, Rep. Inter., 12p.

FERREIRA, F.J.F. 1982. Alinhamentos estruturais-magnéticos da região centro-oriental da Bacia do Paraná e seu significado tectônico. In: Geologia da Bacia do Paraná - reavaliação da potencialidade e prospectividade em hidrocarbonetos. São Paulo, Paulipetro - Consórcio CESP/IPT, p. 143-166.

FÚLFARO, V.J. 1996. Geology of Eastern Paraguay. In COMIN-CHIARAMONTI, P. \& GOMES, C.B., eds., Alkaline magmatism in Eastern Paraguay. Relationships 
with coeval magmatism in Brazil. São Paulo, EDUSP/FAPESP, p. 17-29.

HARRINGTON, H.J. 1950. Geología del Paraguay Oriental. Fac. Ci. Exac. Fís. Nat., Contrib. Cient., Série E, Geología, 1:1-82.

1972. Silurian of Paraguay. In BEVY, B.W.B.N. \& BOUGOT, A.J., eds., Correlation of the South American Silurian Rocks. v. 133: 41-50.

KANZLER, A. 1987. The Southern Precambrian in Paraguay; geological inventory and age relations. Zbl. Geol. Paläont., (7/8): 753-765.

LIVIERES, R.A. \& QUADE, H. 1987. Distribución regional y asentamiento tectónico de los complejos alcalinos del Paraguay. Zbl. Geol. Paläont. (7/8): 791805.

ORUÉ, D. 1996. Sintese da geologia do Paraguai Oriental, com ênfase para o magmatismo alcalino associado. São Paulo, 163p. (Dissertação de Mestrado, Instituto de Geociências, Universidade de São Paulo).

PHOTO GRAVITY CORPORATION. 1991. Regional Bouguer Gravity data and station lacation Map of the Paraguay (Scale 1:2.000.000). Asunción, Archivo DRMMOPC.

PROYECTO PAR 83/005. 1986. Mapa geológico del Paraguay. Assunción, PNUDMDN, Texto Explicativo, 270p.

PUTZER, H. 1962. Die geologie von Paraguay. Beitr. Reg. Geol. Erde, 2:182p.

QUINTAS, M.C.L. 1994. O embasamento da Bacia do Paraná: reconstrução geofisica de seu arcabouço. São Paulo, 218 p. (Tese de Doutoramento, Instituto Astronômico e Geofísico, Universidade de São Paulo).

RENNE, P.R.; ERNESTO, M.; PACCA, I.G.; COE, R.S.; GLEN, J.M.; PRÉVOT, M.; PERRIN, M. 1992. The age of Paraná
Flood Volcanism, rifting of Gondwanaland, and the Jurassic-Cretaceus boundary. Science, 258: 975-979.

RICCOMINI, C.; VELÁZQUEZ, V.F.; GOMES, C.B. 1998. Padrão de fraturamento das rochas alcalinas ultramáficas cenozóicas do Rift de Assunção, Paraguai Oriental. In: CONGRESSO BRASILEIRO DE GEOLOGIA, 40, Belo Horizonte. Anais... Belo Horizonte: SBG, p.109.

THE ANCHUTZ CORPORATION. 1987. Generalized Geological Map Paraguay and Adjacent Areas (Scale 1:2.000.000). Archivo DRM-MOPC, Asunción.

THOMAS \& ASSOCIATES 1976. Preliminary ERTS interpretation southeastern Paraguay. Asunción, DRM-MOPC, Rep. Inter., 20p.

TURNER, S.; REGELOUS, M.; KELLEY, S.; HAWKESWORTH, C.; MANTOVANI, M. 1994. Magmatism and continental break-up in the South Atlantic: high precision ${ }^{40} \mathrm{Ar}-{ }^{39} \mathrm{Ar}$ geochronology. Earth Planet. Sci Lett., 124:333-348.

VELÁZQUEZ V.F., GOMES, C.B.; ORUÉ, D.; COMIN-CHIARAMONTI, P. 1996. Magmatismo alcalino do Paraguai: uma revisão e atualização das províncias. Bol. IG-USP, Sér. Cient., 27:61-79.

VELÁZQUEZ, V.F.; RICCOMINI, C.; GOMES, C.B. 1998. Tectônica mesozóica no Rift de Assunção, Paraguai Oriental. In: CONGRESSO BRASILEIRO DE GEOLOGIA, 40, Belo Horizonte. Anais... Belo Horizonte: SBG, p.112.

VIDOTTI, R.M., EBINGER, C.J., FAIRHEAD, J.D. 1998. Gravity signature of the Paraná Basin, Brazil. Earth Planetary Science Letters, 159:117-132.

WIENS, F. 1986. Zur lithostratigraphischen und strukturellen entwickling des Rio Apa Hoclandes, Nordost Paraguay. Clausth. Geowiss. Diss., 19:280p.

\section{Endereço dos autores:}

- Victor Fernandez Velázquez - Instituto de Geociências, Universidade de São Paulo, Caixa Postal 11.348, 05422-970, São Paulo, SP, Brasil. E-mail: vvf@usp.br - Bolsista de pós-doutorado da Fapesp (Processo 97/00176-7).

- Claudio Riccomini e Celso de Barros Gomes - Instituto de Geociências, Universidade de São Paulo, Caixa Postal 11.348, 05422-970, São Paulo, SP, Brasil. E-mails: riccomin@usp.br, cgomes@usp.br

- Lucia de Figueredo e Carlos Figueredo - Universidad Nacional de Asunción, FACEN - Departamento de Geología - Campus Universitário de la UNA, San Lorenzo, Paraguai. 